\title{
Study Regarding the Imaging and Functional Evaluation in the Rehabilitation of Balance in Patients with Ischaemic Stroke
}

\begin{abstract}
PAUL LUCACl ${ }^{1}$, MARIUS NECULAES ${ }^{2}$, DANISIA HABA ${ }^{1}$
${ }^{1}$ Grigore T. Popa University of Medicine and Pharmacy lasi, 16 University Str., 700115, Iasi, Romania

${ }^{2}$ Alexandru Ioan Cuza University of lasi, Faculty of Physical Education and Sport, 3 Toma Cozma Str., 700554, Iasi, Romania

The present study is based on the paraclinical and functional evaluation of a sample of 66 subjects with ischaemic stroke, to monitor the evolution of their functional parameters. The tests concerning the variation of barycentre speed within the support polygon and the curve length were conducted using the GPS 400 Posturograph, which provided us with information related to the balance of the subjects in an orthostatic stance with eyes open, with eyes closed, looking to the right, looking to the left, head tilted to the right, head tilted to the left, head in extension. Our findings highlight the balance re-education capacity of the subjects with ischaemic stroke through individualised physical therapy programs.
\end{abstract}

Keywords: rehabilitation, swing, functional parameters, testing

The stroke represents one of the main causes of mortality and disability worldwide. This multifactor disorder involves both modifiable risk factors (diabetes, hypertension, smoking), and non-modifiable variables, such as age, gender, family history [1].

An independent factor, extremely important, is obesity, associated with high risk for cardiovascular diseases such as ischaemic and haemorrhagic stroke. For each five-point increase in body mass index, the risk of a stroke is estimated to increase by up to $18 \%$ [2] .

The risk of stroke relapse is high, and the secondary prevention strategies depend on the etiopathology of the disorder. Around a third of ischaemic strokes do not have a clear cause; they may be the result of cardiovascular conditions such as occult atrial fibrillation, aortic arch atheroma, septal defect, genetic factors, etc [3].

Carotid atherosclerosis represents the third cause of ischaemic stroke, as the internal and external carotids have their origin in the common carotid aorta. Some studies suggest that the bifurcation angle between the two arteries may favour the emergence of atheroma, while other studies deny such hypothesis [4].

Several studies within the last decade have show $n$ that the short-term and long-term effects of a stroke, in general, have improved after thrombolysis and through a more effective management of risk factors, before and after stroke occurrence [5].

Studies on rehabilitation after acute stroke, have found that the most important predictors of recovery are represented by gender, age, severity, size and subtype of stroke [6].

Reperfusion represents an important factor concerning the subsequent result of recovery [7]. Perfusion refers to blood circulation that carries nutrients and oxygen to the tissue within the brain, usually quantified classically as blood volume per unit of brain tissue, usually measured in $\mathrm{mL} / 100 \mathrm{~g} /$ minute [8].

Computed tomography is still regarded as the best way to diagnose a stroke; it is very efficient in making the distinction between an ischaemic and a haemorrhagic stroke $[9,10,11]$.

Magnetic resonance imaging is useful in the diagnosing of an ischaemic stroke, thus enabling professional to find the optimal treatment strategies, but the long scanning duration is a serious impediment compared to computed tomography [12].

Postural deficiencies are common in case of strokes; there is correlation between the asymmetry of barycentre distribution and the severity of stroke. Most individuals who suffer from this disorder distribute less weight on the plegic lower limb in the standing position [13].

Many chronic survivors of stroke feature a high risk of losing balance during gait. As it occurs for all people, the loss of balance may be caused by external mechanical disturbances, but stroke survivors are more prone to falls, not because of environmental factors, but due to specific balance control deficits [14,15].

Over $80 \%$ of the patients who suffer a first stroke have stability deficits associated with a low recovery of selfserving capacity and with high risk of falling [16].

Retrieving the symmetrical distribution of weight and the ability to change the barycentre was mentioned as an essential objective in the process of gait and balance rehabilitation in case of patients with chronic stroke [17].

Taking into account the negative consequences of balance deficits after the stroke and the long-term consequences, it is critical to identify the gravity of this problem [18].

It has been demonstrated that the asymmetry of spatiotemporal parameters of gait lead to the reduction of velocity [19] and to the decrease in the clinical scores for balance assessment [20, 21].

\section{Experimental part \\ Materials and methods}

The study conducted was prospective and it comprised a sample of 66 hemiplegic subjects, 31 female subjects and 35 male subjects who suffered an ischaemic stroke. The sample was selected within the Prof. dr. Nicolae Oblu Clinical Emergency Hospital, lasi, as well as within the Clinical Recovery Hospital lasi, and the study unfolded in the period March 2016 - October 2018. From among the subjects, 29 were right-side hemiplegic and 37 left-side hemiplegic, all of them within the first 6 months after the occurrence of a stroke. 


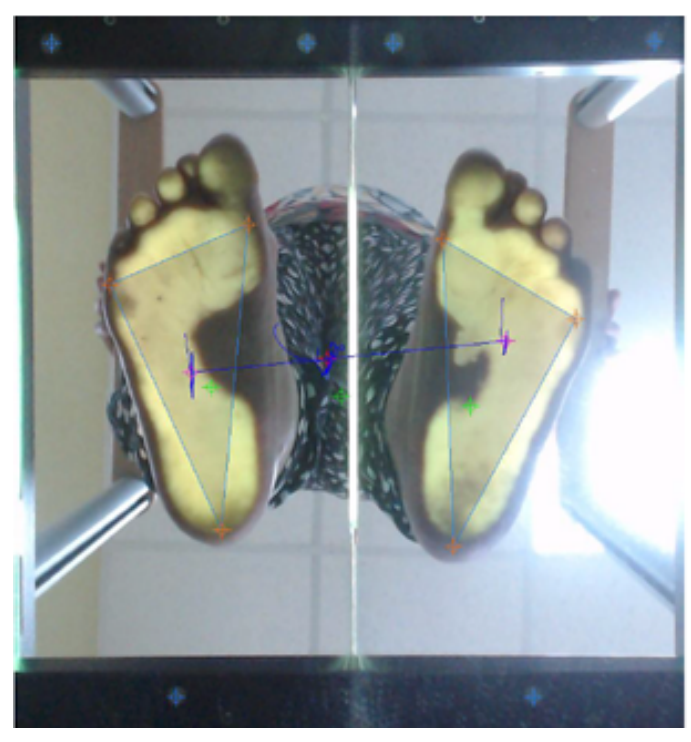

Besides the medical emergency management, the neurological clinical examination and the imaging evaluation using computed tomography, some of the subjects also benefited from head MRIs to determine the extent of the brain lesion and to identify the possible structural anomalies. We have conducted the functional assessment using the Posturograph at the beginning of the rehabilitation program and a follow-up after six months, during which they followed individualised physical therapy programs, three times a week. Using the GPS 400 stabilometric platform within the Posturograph, which has pressure sensors and tests bodyweight distribution on the lower limbs [22], we have analysed at the same time the speed of the oscillations and barycentre curve length, providing information regarding the direction and range of the body's lack of balance. The principle of this device is to analyse the variation of barycentre within the support polygon in orthostatic position (fig 1). The evaluation was conducted by taking into account several balance parameters in various types of tests (with eyes open, with eyes closed, looking to the right, looking to the left, head tilted to the right head tilted to the left, head in extension). The targeted parameters were the velocity of barycentre oscillations within the support polygon, measured in $\mathrm{mm} /$ $\mathrm{s}$, and curve length, measured in $\mathrm{mm}$ (fig. 1).

\section{Testing method}

-the patients were explained the testing technique, namely maintaining the bipodal orthostatic stance on the stabilometric platform, without support.

-feet were placed in a parallel position, slightly apart, with a natural, motionless body posture.

-the testing lasted for $20 \mathrm{~s}$ for each evaluation method: with eyes open, with eyes closed, looking to the right, looking to the left, head tilted to the right, head tilted to the

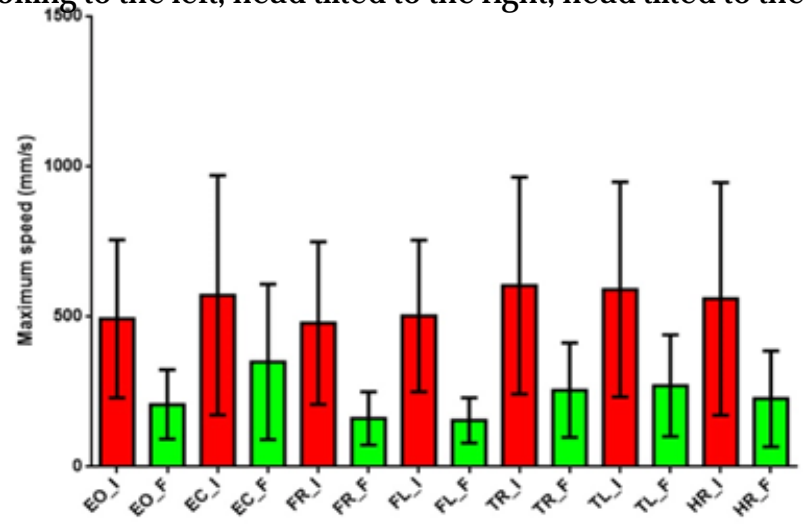

Fig 1. Barycentre position within the support polygon and curve length

left, head in extension, to prevent the onset of muscle fatigue, which may lead to intense postural or balance reactions or important deviations of the barycentre.

-the initial testing was conducted at the beginning of the study and the final testing after six months of physical therapy.

The inclusion criteria for the subjects within the study were as follows:

-The stroke had to be ischaemic

-The stroke must have concerned the middle cerebral artery area

-The subject has to be able to maintain the orthostatic stance

-The localisation and the type of stroke must have been proven via imaging examination

-The patient must be in the first six months post-stroke

The exclusion criteria were the following:

-Failure to meet the inclusion criteria

-Retractures of the Achilles tendon and varus and equinus foot

-The patient's refusal to return for the follow-up after the recoveryperiod

-Cerebellum disorders or balance disturbances due to inner ear pathology.

\section{Results and discussions}

The research was represented by a prospective study of comparative analysis of balance alterations after an ischaemic stroke and its re-education through physical therapy for 6 months. The results were analysed separately for the right-side hemiplegic subjects and the left-side ones, using the One-Way Anova test.

Within the initial and final evaluation of the speed of barycentre oscillations within the support polygon, it is worth noting the favourable evolution of the right-side hemiplegic subjects, from the evaluation conducted at the

Fig 2. The speed of barycentre oscillations $(\mathrm{mm} / \mathrm{s})$, right-side hemiplegia, initial evaluation with eyes open (EO_I) and final (EO_F), initial evaluation with eyes closed (EC_I) and final (EC_F), initial evaluation face to the right (FR_I) and final (FR_F), initial evaluation face to the left (FL_I) and final (FL_F), initial evaluation head tilted to the right (TR I) and final (TR $\bar{F})$, initial evaluation head tilted to the left $\left(T L_{-}\right)$) and final $\left(T L_{-} \bar{F}\right)$, initial evaluation head retroflexed (HR_I) and final (HR_F). 
beginning of the physical therapy program to the one held upon ending the treatment and monitoring period (fig. 2).

As illustrated in figure 2, the speed of barycentre oscillations within the support polygon decreased for rightside hemiplegic subjects, which stands for an improvement of balance and enhanced motor control $(P \leq 0.0001)$. From a mean of $520.36 \mathrm{~mm} / \mathrm{s}$ (standard deviation \pm 262.4 ; $n=29$ ) at the initial evaluation within the evaluation with eyes open, the subjects dropped at the end of the treatment and monitoring period within the study to a mean of the speed of barycentre oscillations of $222.21 \mathrm{~mm} / \mathrm{s}$ (standard deviation $\pm 115.4 ; n=29$ ).

For all types of testing, we have recorded improvements of the speed of barycentre oscillations, thus dropping from mean initial values of $551.92 \mathrm{~mm} / \mathrm{s}$ with eyes closed (standard deviation $\pm 398.8 ; n=29$ ), $519.52 \mathrm{~mm} / \mathrm{s}$ (standard deviation $\pm 270.7 ; n=29$ ) face to the right, 524.45 $\mathrm{mm} / \mathrm{s}$ (standard deviation $\pm 252.4 ; \mathrm{n}=29$ ) face to the left, $563.16 \mathrm{~mm} / \mathrm{s}$ (standard deviation $\pm 361.1 ; \mathrm{n}=29$ ) head tilted to the right, $538.65 \mathrm{~mm} / \mathrm{s}$ ( standard deviation \pm 357.4 ; $\mathrm{n}=29$ ) head tilted to the left, $556,03 \mathrm{~mm} / \mathrm{s}$ (standard deviation $\pm 387.3 ; n=29$ ) head retroflexed, to considerably lower mean final values of $311.14 \mathrm{~mm} / \mathrm{s}$ (standard deviation $\pm 258.9 ; n=29$ ) with eyes closed, $295.18 \mathrm{~mm} / \mathrm{s}$ (standard deviation $\pm 88.82 ; n=29$ ) face to the right, 218.38 $\mathrm{mm} / \mathrm{s}$ (standard deviation $\pm 75.45 ; \mathrm{n}=29$ ) face to the left, $255.26 \mathrm{~mm} / \mathrm{s}$ (standard deviation $\pm 157.2 ; n=29$ ) head tilted to the right, $270.24 \mathrm{~mm} / \mathrm{s}$ (standard deviation \pm 169.4 ; $\mathrm{n}=29$ ) head tilted to the left, $226.78 \mathrm{~mm} / \mathrm{s}$ (standard deviation \pm 159 .8; $n=29$ ) head retroflexed.

The reduced speed of barycentre oscillations is due to the increase in plantar proprioception and in the muscle tone of the plegic leg. According to several studies, the difficulties related to balance re-education are closely related to age, gender and localisation of the stroke [6].

In case of left-side hemiplegic patients, we have also noted an improvement of balance $(P \leq 0.0001)$ through a decrease in the speed of barycentre oscillations within the support polygon from the initial evaluation to the final evaluation (fig. 3).

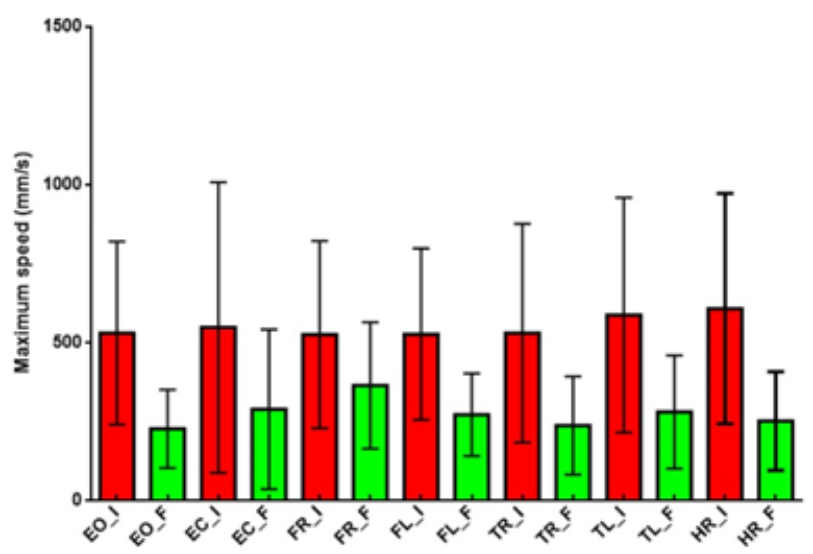

Fig 3. The speed of barycentre oscillations $(\mathrm{mm} / \mathrm{s})$, left-side hemiplegia, initial evaluation with eyes open (EO_I) and final

$\left(E O_{-} F\right)$, initial evaluation with eyes closed (EC_I) and final (EC_F), initial evaluation face to the right (FR_I) and final (FR_F), initial evaluation face to the left ( $\left.F L_{-} I\right)$ and final ( $\left.F L_{-} F\right)$, initial evaluation head tilted to the right $\left(T_{-} I\right)$ and final $\left(T_{-} \bar{F}_{-}\right)$, initial evaluation head tilted to the left $\left(T_{-} L_{-}\right)$and final $\left(T L_{-} \bar{F}\right)$, initial evaluation head retroflexed (HR_I) and final (HR_F)

As illustrated in figure 3 , the values of barycentre oscillation speed within the support polygon decreased from the initial average values of $514,07 \mathrm{~mm} / \mathrm{s}$ (standard deviation \pm 289.6; $n=37$ ) with eyes open, $553.14 \mathrm{~mm} / \mathrm{s}$ (standard deviation \pm 459.3; $n=37$ ) with eyes closed,
$506,08 \mathrm{~mm} / \mathrm{s}$ (standard deviation $\pm 296.2 ; \mathrm{n}=37$ ) face to the right, $517.76 \mathrm{~mm} / \mathrm{s}$ (standard deviation $\pm 270.9 ; n=37$ ) face to the left, $555.47 \mathrm{~mm} / \mathrm{s}$ (standard deviation \pm 345.7 ; $\mathrm{n}=37$ ) head tilted to the right, $589.27 \mathrm{~mm} / \mathrm{s}$ (standard deviation $\pm 371.7 ; n=37$ ) head tilted to the left, 595.56 $\mathrm{mm} / \mathrm{s}$ (standard deviation $\pm 364.3 ; \mathrm{n}=37$ ) head retroflexed, to the mean final values of $218.72 \mathrm{~mm} / \mathrm{s}$ (standard deviation $\pm 123.7 ; n=37$ ) with eyes open, $314.17 \mathrm{~mm} / \mathrm{s}$ (standard deviation $\pm 252.7 ; n=37$ ) with eyes closed, $279.14 \mathrm{~mm} / \mathrm{s}$ (standard deviation $\pm 199.9 ; n=37$ ) face to the right, 221.18 $\mathrm{mm} / \mathrm{s}$ (standard deviation $\pm 130.6 ; n=37$ ) face to the left, $244.56 \mathrm{~mm} / \mathrm{s}$ (standard deviation $\pm 155.6 ; n=37$ ) head tilted to the right, $276.02 \mathrm{~mm} / \mathrm{s}$ (standard deviation \pm 179.4 ; $\mathrm{n}=37$ ) head tilted to the left, $244.74 \mathrm{~mm} / \mathrm{s}$ (standard deviation $\pm 156.2 ; n=37$ ) head retroflexed. Mobility exercises, accompanied by muscle toning exercises, finally lead to an improvement of body balance in case of ischaemic stroke. Other studies highlight that breathing muscle toning may lead to an improvement of torso stability among patients with stroke [16].

Within the initial and final evaluation of barycentre curve length, we have also found a favourable evolution of balance among right-side hemiplegic patients $(p \leq 0.0001)$, from the initial evaluation to the final evaluation (fig. 4).

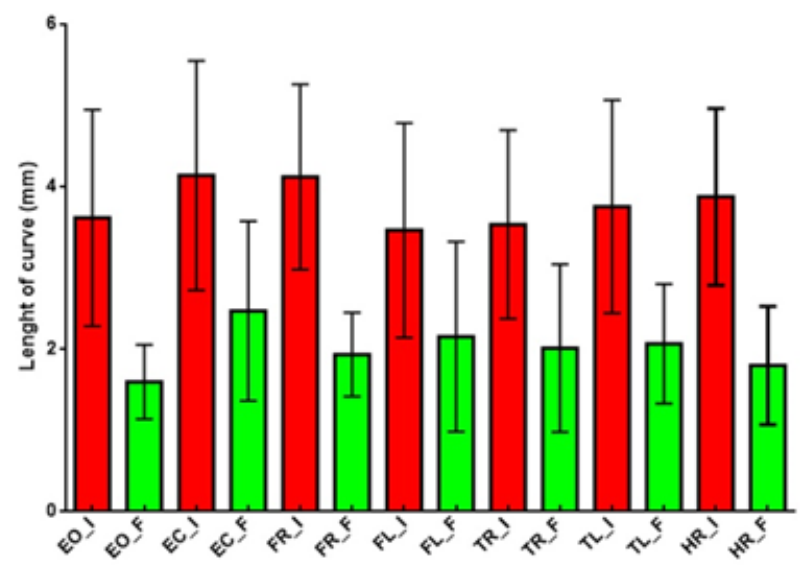

Fig 4. Barycentre curve length $(\mathrm{mm})$, right-side hemiplegia, initial evaluation with eyes open (EO I) and final (EO F), initial evaluation with eyes closed $\left(E_{-} C_{-}\right)$and final $\left(E_{-}^{-} F\right)$, initial evaluation face to the right ( $\left.F R_{-}{ }_{-}\right)$and final $\left(F R_{-} \bar{F}\right)$, initial evaluation face to the left (FL_I) and final (FL_F), initial evaluation head tilted to the right (TR I) and final (TR_F $)$, initial evaluation head tilted to the left ( $\left.T L_{-} \bar{I}\right)$ and final $\left(T L_{-} \bar{F}\right)$, initial evaluation head retroflexed (HR_l) and final (HR_F)

According to figure 4, the initial average values ale of barycentre curve length for the right-side hemiplegic subjects were de $3.603 \mathrm{~mm}$ (standard deviation \pm 1.332 ; $n=29$ ) with eyes open, $4.037 \mathrm{~mm}$ (standard deviation \pm 1.412; $n=29$ ) with eyes closed, $3.694 \mathrm{~mm}$ (standard deviation $\pm 1.140 ; n=29$ ) face to the right, $3.659 \mathrm{~mm}$ (standard deviation $\pm 1.321 ; n=29$ ) face to the left, 3.582 $\mathrm{mm}$ (standard deviation $\pm 1.160 ; n=29$ ) head tilted to the right, $3.669 \mathrm{~mm}$ (standard deviation $\pm 1.311 ; n=29$ ) head tilted to the left, $3.916 \mathrm{~mm}$ (standard deviation \pm 1.088 ; $n=29$ ) head retroflexed. To the final evaluation, the subjects scored lower mean values of barycentre curve length, namely $1.558 \mathrm{~mm}$ (standard deviation $\pm 0.4581 ; n=29$ ) with eyes open, $2.379 \mathrm{~mm}$ (standard deviation \pm 1.105 ; $\mathrm{n}=29$ ) with eyes closed, $2.471 \mathrm{~mm}$ (standard deviation \pm $0.5157 ; n=29$ ) face to the right, $1.971 \mathrm{~mm}$ (standard deviation $\pm 1.170 ; n=29$ ) face to the left, $2,013 \mathrm{~mm}$ (standard deviation $\pm 0.1 .032 ; n=29$ ) head tilted to the right, $2.067 \mathrm{~mm}$ (standard deviation $\pm 0.7379 ; n=29$ ) head tilted to the left, $1.798 \mathrm{~mm}$ (standard deviation \pm 0.7275 ; 
$n=29$ ) head retroflexed. The asymmetry of balance linear control caused by the impaired capacity of the plegic lower limb concerning swing control leads to a decrease in gait capacity [23]. Hence, balance and stability exercises must target an efficient postural control and an optimisation of the plegic lower limb swing.

A notable improvement of barycentre curve length is also observed in case of left-side hemiplegic patients, where we obtained values highlighting the improvement of balance $(P \leq 0.0001)$ from the initial evaluation to the final evaluation (fig. 5).

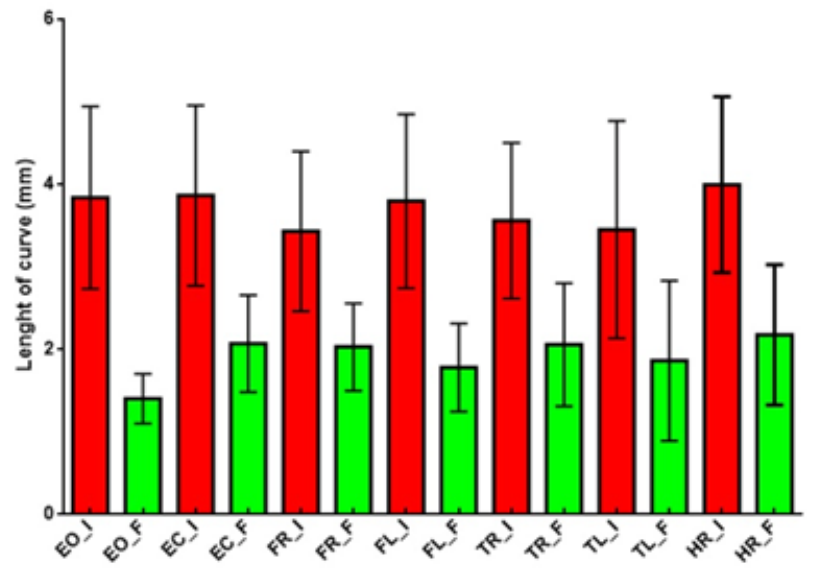

Fig 5. Barycentre curve length ( $\mathrm{mm}$ ), left-side hemiplegia, initial evaluation with eyes open (EO I) and final (EO F), initial evaluation with eyes closed (EC_l) and final $\left(E_{-}^{-} C_{-}\right)$, initial evaluation face to the right ( $F R-I)$ and final (FR $\bar{F}$ ), initial evaluation face to the left ( $\left.F L_{-} I\right)$ and final ( $F L_{-} F$ ), initial evaluation head tilted to the right (TR_I) and final (TR_F $)$, initial evaluation head tilted to the left (TL $\bar{I})$ and final $(T L \bar{F})$, initial evaluation head retroflexed (HR_l) and final (HR_F)

Figure 5 illustrated that the average values of barycentre curve length were initially $3.766 \mathrm{~mm}$ (standard deviation $\pm 1.105 ; n=37$ ) with eyes open, $4.004 \mathrm{~mm}$ (standard deviation $\pm 1.093 ; n=37$ ) with eyes closed, $3.733 \mathrm{~mm}$ (standard deviation $\pm 0.9683 ; n=37$ ) face to the right, $3.679 \mathrm{~mm}$ (standard deviation $\pm 1.053 ; \mathrm{n}=37$ ) face to the left, $3.498 \mathrm{~mm}$ (standard deviation $\pm 0.9438 ; n=37$ ) head tilted to the right, $3.597 \mathrm{~mm}$ (standard deviation \pm 1.317 ; $\mathrm{n}=37$ ) head tilted to the left, $3.896 \mathrm{~mm}$ (standard deviation \pm 1.066 ) head retroflexed, finally reaching improved values of $1.496 \mathrm{~mm}$ (standard deviation $\pm 0.3009 ; n=37$ ) with eyes open, $2.269 \mathrm{~mm}$ (standard deviation $\pm 0.5862 ; n=37$ ) with eyes closed, $1.988 \mathrm{~mm}$ (standard deviation \pm 0.5301 ; $\mathrm{n}=37$ ) face to the right, $1.934 \mathrm{~mm}$ (standard deviation \pm $0.5327 ; \mathrm{n}=37$ ) face to the left, $2.003 \mathrm{~mm}$ (standard deviation $\pm 0.7454 ; n=37$ ) head tilted to the right, 1.962 $\mathrm{mm}$ (standard deviation $\pm 0.9699 ; n=37$ ) head tilted to the left, $1.998 \mathrm{~mm}$ (standard deviation $\pm 0.8494 ; n=37$ ) head retroflexed.

According to our findings, the values of the speed of barycentre oscillations (fig 2.3) and the values of barycentre curve length (fig 4.5) have improved for both right-side and left-side hemiplegic patients, after undergoing the physical therapy programs. The optimisation of these values of the parameters assessed was reflected in better balance, increased motor control and improved gaitspeed of the subjects.

Modern studies underpin that gait exercises on the treadmill in front of a mirror may have effects on the lower limb muscle toning and on voluntary motor capacities and the gaitspeed, implicitly [24]. Furthermore, assisted robotic therapy has positive effects on balance re-education [25].
The patients with post-stroke sequelae use abnormal compensatory movements to optimise gait, hence such elements should be taken into accountduring rehabilitation [13].

Gait ability is influenced by several factors, among which body balance while standing, spatial coordination and orientation, body balance while sitting. The analysis of shifts in the pressure centre while sitting indicates increased postural disturbances in patients with stroke. A platform device, due to non-invasive, easy and quick measurements, should be a great choice of a tool for the evaluation of postural deficits. Itmay also be used to evaluate the process of rehabilitation post-stroke [26]. Another study that used the posturographic evaluation of the patients with stroke has fond that balance re-education should also include exercises on unstable surfaces while sitting, to tone the torso muscles [27]. Specific training has led to an increase in the speed and precision of the changing capacity recorded by the barycentre, by reducing the duration of bodyweight transfer between the lower limbs, in 12 weeks, according to a study on a sample of 36 subjects with stroke [28]. Another study that used the posturographic evaluation indicates that, after a 30-day period of rehabilitation, the speed of barycentre oscillations with eyes open and closed reduced, which suggests the brain's capacity of reacting to external stimuli (physical therapy) [29]. The balance rehabilitation activities through double-task training show significant improvements of weight distribution index and of plegic lower limb stability with eyes open [30].

\section{Conclusions}

The functional evaluation, along with the clinical and paraclinical examination, plays a very important role in the rehabilitation of balance in patients with ischaemic stroke. By getting to know the postural dysfunctions emerged upon the evaluation and monitoring of the speed of barycentre oscillations within the support polygon and of barycentre curve length lead to an orientation and optimisation of medical rehabilitation programs.

The imaging evaluation is highly necessary to identify focal lesions and to determine the impaired brain area.

Physical therapy represents an efficient body balance re-education means, a fact reflected in a reduction of the speed of barycentre oscillations and in a decrease of oscillation curve length of the barycentre.

An extended monitoring of rehabilitation for the patients with ischaemic stroke is necessary in order to adopt the physical therapy plan to the necessities emerged depending on the evolution of the remaining function among the subjects.

\section{References}

1.VASUDEVA, K., MUNSHI, A., Int] Neurosc, 129, no 5, 2018, p. 511-522. 2.DARKE, S., DUFLOU, J., KAYE, S., FARRELL, M., LAPPIN, J., J Forensic Leg Med, 63, 2019, p. 1-6.

3.SCHULZ, U. G., Maturitas, 122, 2019, p. 44-50.

4.NOH, SM., KANG, HG., Sci Rep. 9-4619, 2019.

5.EMMETT, E. S., DOUIRI, A., MARSHALL, I. J., WOLFE, C. D. A., RUDD, A. G., BHALLA, A., Plos One, 14, no 2, 2019.

6.MUSA, K. I., \& KEEGAN, T. J., Plos One, 13, no 12, 2018.

7.CLUA-ESPUNY, JL., ABILLEIRA, S., QUERALT-TOMAS, L., GONZALEZ-HENARES, A., GIL-GUILLEN, V., MURIA-SUBIRATS, E., BALLESTA-ORS, J., Cardiol Res. 10, no 2, 2019, p. 87-97.

8.YAO, Y., ZHANG, S., TANG, X., ZHANG, S., SHI, J., ZHU, W., ZHU, W., Clin Radiol, 71, no 9, 2016, p. 938.

9.PILISZEK, A., WITKOW SKI, G., SKLINDA, K., SZARY, C., RYGLEWICZ, D., DOROBEK, M., \& WALECKI, J., Neurol Neurochir Pol. 50, no 4, 2016, p. 241-250. 
10.OEI, M. T. H., MEIJ ER, F. J. A., VAN DER WOUDE, W.-J ., SMIT, E. J., VAN GINNEKEN, B., MANNIESING, R., \& PROKOP, M., Eur Radiol. 27, no 6, 2017, p. 2411-2418.

11.AYEKPAM, M., CHALLAM, R., SHAFI, F., J Evol Med Dent Sci. 4, no 101, 2015, p. 16638-16641.

12.CHUNG, MS., LEE, JY., JUNG, SC., BAEK, S., SHIM, WH., PARK, JE., KIM, HS., CHOI, CG., KIM, SJ ., LEE, DH., JEON, SB., KANG, DW., KWON, SU., KIM, JS., Eur Radiol. 29, no 5, 2019, p. 2641-2650.

13.FEHER-KISS, A., NAGY, E., DOMJAN, A., JAKAB, K., KRANICZ, J., \& HORVATH, G., Top Stroke Rehabil. 25, no 8, 2018, p. 561-568.

14.STIMPSON, K. H., HEITKAMP, L. N., EMBRY, A. E., \& DEAN, J. C., Gait Posture, 70, 2019, p. 136-140.

15.J ORGENSEN, L., ENGSTAD, T., JACOBSEN, BK., Stroke, 33, no 2, 2002.

16.LEE, K., PARK, D., \& LEE, G., J Stroke Cerebrovasc Dis. 28, no 5, 2019, p. 1200-1211.

17.MIRANDA, C. S., OLIVEIRA, T. DE P., GOUVEA, J. X. M., PEREZ, D. B., MARQUES, A. P., \& PIEMONTE, M. E. P., Games Health J. 8, no 4, 2019.

18.VINCENT-ONABAJ O, G., MUSA, H. Y., \& J OSEPH, E., J Stroke Cerebrovasc Dis. 27, no 12, 2018, p. 3487-3492.

19.PATTERSON, K.K., GAGE, W.H., BROOKS, D., BLACK, S.E., MCILROY, W.E., Gait Posture, 31, no 2, 2010, p. 241-246.
20.LEWEK, M.D., BRADLEY, C.E., WUTZKE, C.J ., ZINDER, S.M., J Appl Biomech. 30, no 1, 2014, p. 31-36.

21.MIEVILLE, C., LAUZIĖRE, S., BETSCHART, M., NADEAU, S., \& DUCLOS, C., J Electromyogr Kinesiol. 41, 2018, p. 41-49.

22.NECULAES, M., BOTEZ, P., Sp Soc, 11, no 2, 2011, p. 206-221.

23.HENDRICKSON, J., PATTERSON, KK., INNESS, EL., MCILROY, WE., MANSFIELD, A., Gait Posture, 39, no 1, 2014, p. 177-181.

24.BRODERICK, P., HORGAN, F., BLAKE, C., HICKEY, P., O'REILLY J ., EHRENSBERGER M., SIMPSON, D., ROBERTS, D., MONAGHAN, K., Physiother Theory Pract. 35, no5, 2019, p. 478-488.

25.ZHENG, QX., GE, L., WANG, CC., MA, QS, LIAO, YT., HUANG, PP., WANG, GD., XIE, QL., RASK, M., Int J Nurs Stud. 95, 2019, p. 7-18. 26.GENTHON, N., VUILLERME, N., MONNET, J. P., PETIT, C., ROUGIER, P., Clin Biomech. 22, no 9, 2007, p. 1024-1029.

27.NES, I. J. W. VAN, NIENHUIS, B., LATOUR, H., \& GEURTS, A. C. H., Gait Posture, 28, no 3, 2008, p. 507-512.

28.DE HAART, M., GEURTS, A. C., DAULT, M. C., NIENHUIS, B., \& DUYSENS, J., Arch Phys Med Rehabil. 86, no 4, 2005, p. 755-762.

29.RONGIES, W., STOMKA, B., DUCZEK, A., \& DOLECKI, W., J STROKE CEREBROVASC DIS. 26, no 2, 2017, p. 34-37.

30.CHOI, J. H., KIM, B. R., HAN, E. Y., \& KIM, S. M., Ann Rehabil Med. 39, no 1, 2015, p. 81-90.

Manuscript received: 16.11 .2018 